\title{
A UTILIZAÇÃO DO ZOOLÓGICO CIGS COMO FERRAMENTA PARA O ENSINO DA BIODIVERSIDADE AMAZÔNICA
}

\author{
THE USE OF CIGS ZOO AS A TOOL FOR TEACHING \\ AMAZON BIODIVERSITY
}

\section{EL USO DE CIGS ZOO COMO HERRAMIENTA PARA ENSENAR LA BIODIVERSIDAD AMAZONICA}

\author{
Rebeca Brandão Nascimento ${ }^{1}$; Philippe Nascimento da Costa ${ }^{2}$; Adriano Teixeira de \\ Oliveira $^{3}$; Rosiane Cardoso Corrêa ${ }^{4}$; Kátia Cilene Lopes Calderaro ${ }^{5}$
}

\begin{abstract}
Resumo
A discussão da biodiversidade é um assunto bastante importante para ser debatido. Uma alternativa para essas discussões são os espaços escolares e a utilização de aulas práticas, para contextualização dos conteúdos trabalhados em sala de aula. Os zoológicos são ambientes com grande potencial para serem utilizados com esse fim, pois nesse ambiente podemos encontrar espécies raras ou ameaçadas, promovendo assim o desenvolvimento do pensamento ecológico. Com isso, este trabalho busca desenvolver a importância da biodiversidade amazônica com a utilização de uma sequência didática a partir de uma visita de campo no Zoológico CIGS. Nesta atividade participaram 159 alunos do 7 ano do Ensino Fundamental - Anos finais. Os alunos utilizaram uma ficha de coleta desenvolvida para a atividade, e após a coleta de dados, foram analisados pelos alunos em sala de aula, compartilhando com os grupos e contextualização com a mediação da professora e por fim os alunos concluíram com a importância de preservar a biodiversidade amazônica.
\end{abstract}

Palavras-chave: Biodiversidade; Ensino de Ciências; Zoologia; Zoológico; Aprendizagem.

${ }^{1}$ Mestranda no Programa de Pós - Graduação Profissional em Ensino Tecnológico do Instituto Federal de Educação, Ciência e Tecnologia do Amazonas (IFAM). Manaus, AM - Brasil. E-mail: rebecabrandaon@gmail.com

${ }^{2}$ Mestrado em Ensino de Ciências e Matemática - Universidade Federal do Amazonas (UFAM). Manaus, AM - Brasil. Professor do Secretaria de Estado de Educação e Desporto (SEDUC-AM). Manaus, AM Brasil. E-mail: philippenascimentodacosta@gmail.com

${ }^{3}$ Doutorado em Diversidade Biológica pela Universidade Federal do Amazonas (UFAM). Manaus, AM- Brasil. Professor do Instituto Federal de Educação, Ciência e Tecnologia do Amazonas. Manaus, AM Brasil. E-mail: adriano.oliveira@ifam.edu.br

${ }^{4}$ Mestrado em - Ciência da Educação - Universidade Federal do Pará (UFPA). Belém, PA Brasil. Coordenadora Pedagógica na empresa Centro Educacional La Salle. Manaus, AM - Brasil. E-mail: rosiane.correa@lasalle.org.br

${ }^{5}$ Mestrado em Educação - Universidade Federal do Amazonas (UFAM). Manaus, AM - Brasil. Coordenadora Pedagógica do Ensino Médio do Centro Educacional La Salle. Manaus, AM - Brasil. E-mail: katia.calderaro@lasalle.org.br 


\begin{abstract}
The discussion of biodiversity is a very important issue to be debated. An alternative to these discussions is the school spaces and the use of practical classes, to contextualize the contents worked in the classroom. Zoos are environments with great potential to be used for this purpose, because in this environment we can find rare or threatened species, thus promoting the development of ecological thinking. With this, this work seeks to develop the importance of Amazonian biodiversity with the use of a didactic sequence from a field visit at the CIGS Zoo. In this activity 159 students from the 7th year of Elementary School participated - Final years. The students used a collection form developed for the activity, and after the data collection, they were analyzed by the students in the classroom, sharing with the groups and contextualization with the mediation of the teacher and finally the students concluded with the importance of preserving Amazonian biodiversity.
\end{abstract}

Keywords: Biodiversity; Science teaching; Zoology; Zoo; Learning.

\title{
Resumen
}

La discusión de la biodiversidad es un tema muy importante a debatir. Una alternativa a estas discusiones son los espacios escolares y el uso de clases prácticas, para contextualizar los contenidos trabajados en el aula. Los zoológicos son ambientes con gran potencial para ser utilizados con este fin, pues en este ambiente podemos encontrar especies raras o amenazadas, promoviendo así el desarrollo del pensamiento ecológico. Con esto, este trabajo busca desarrollar la importancia de la biodiversidad amazónica con el uso de una secuencia didáctica de una visita de campo en el Zoológico CIGS. En esta actividad participaron 159 alumnos del $7^{\circ}$ año de Primaria Últimos años. Los estudiantes utilizaron un formulario de recolección desarrollado para la actividad, y luego de la recolección de datos, fueron analizados por los estudiantes en el aula, compartiendo con los grupos y contextualización con la mediación del docente y finalmente los estudiantes concluyeron con la importancia de preservar la Amazonía. biodiversidad.

Palabras-clave: Biodiversidad; Enseñanza de las ciencias; Zoología; Zoo; Aprendiendo.

$$
* * *
$$

\section{Introdução}

A sociedade vem crescendo cada vez mais, com esse crescimento o homem desenvolveu muitos avanços tecnológicos, onde nesse processo a biodiversidade acaba sendo ameaçada, pois o ser humano não desenvolveu essa responsabilidade do cuidado com o ambiente. As escolas são ótimos espaços para discutir a importância da biodiversidade, porém os assuntos são apresentados na maioria das vezes de forma expositiva, onde este assunto não é contextualizado com o ambiente que o indivíduo vive.

Uma alternativa utilizada pelas escolas é a utilização de aulas práticas, para contextualização dos conteúdos trabalhados em sala de aula. A partir desse cenário as aulas práticas são ótimas alternativas para a contextualização dos conteúdos dentro do tema biodiversidade. Os zoológicos são ambientes com grande potencial para serem utilizados com esse fim, pois nesse ambiente podemos encontrar espécies raras ou ameaçadas, promovendo assim o desenvolvimento do pensamento ecológico. A educação dentro dos zoológicos é bastante enriquecedora, pois dissemina informações sobre a flora e fauna regional, ajudando a formar atitudes positivas em relação à conservação do meio ambiente, despertando nos visitantes a sensibilização e o pensamento em relação a diversidade biológica e a importância de cuidar da biodiversidade (GARCIA, 2006). 
DOI: https://doi.org/10.46667/renbio.v14i2.592

Com isso, este trabalho busca desenvolver a importância da biodiversidade amazônica com a utilização de uma sequência didática a partir de uma visita de campo no Zoológico CIGS. Nesta atividade participaram 159 alunos do 7 ano do Ensino Fundamental - Anos finais. Os alunos utilizaram uma ficha de coleta desenvolvida para a atividade, e após a coleta de dados, foram analisados pelos alunos em sala de aula, compartilhando com os grupos e contextualização com a mediação da professora e por fim os alunos concluíram com a importância de preservar a biodiversidade amazônica.

\section{Procedimentos metodológicos}

\section{1 Área de estudo e participantes da pesquisa}

Foi utilizada para essa pesquisa a abordagem da pesquisa qualitativa, usando a técnica de pesquisa participativa e aplicada. A pesquisa foi feita no Zoológico do Centro de Instrução de Guerra na Selva - ZOO CIGS, localizado na cidade de Manaus, Amazonas, no ano de 2019. Para o desenvolvimento dessa pesquisa contou-se com a participação de alunos do Anos Finais, das turmas do $7^{\circ}$ ano (159 alunos) do Centro Educacional La Salle - Manaus, que apresentam faixa etária entre 11 a 13 anos.

O Zoológico do Centro de Instrução de Guerra na Selva - ZOO CIGS, foi pensado e construído sob o comando do Tenente Coronel Jorge Teixeira.

O Zoológico do CIGS é um espaço destinado à manutenção de coleções de animais com fins de exibição, reprodução, conservação e educação ambiental, apresentando a rica fauna e flora presente na região. No Zoológico podemos encontrar muitos projetos educativos, científicos e culturais, contribuindo para a conservação da fauna e da flora, e para a formação do cidadão.

Sua inauguração aconteceu em março de 1967, ocupando uma área de $6.000 \mathrm{~m}^{2}$, coberta em sua maior parte de vegetação amazônica, o Zoológico do CIGS aloja 469 animais, sendo 52 mamíferos, 33 aves, 107 répteis e 265 peixes, totalizando uma riqueza de 68 espécies.

Para a realização dessa proposta, foi realizada uma visita de diagnóstico no zoológico, onde foram mapeados os principais pontos para trabalhar dentro da sequência didática. Esses pontos foram: 1) Entrada do Zoológico, onde as principais informações sobre o mesmo estão disponíveis; 2) O Aquário, que apresenta as principais espécies de peixes amazônicos; 3) A Oca do Conhecimento Ambiental, que disponibiliza um servidor para interagir com os grupos de visitantes apresentando um vídeo educativo sobre o zoológico Cigs e a sua importância ambiental; 4) Jabutis; 5) Sala entomológica; 6) Cobras; 7) Araras; 8) Jacaré; 9) Anta; 10) Gavião real; 11) Tartaruga da amazônia; 12) Tucanos; 13) Porco do mato; 14) Gato do mato; 15) Macacos; 16) Papagaios e 17) Onças. 


\subsection{A sequência didática}

A sequência didática utilizada foi baseada a partir de um projeto educacional com o tema: "Preservação da biodiversidade: Qual é minha parte nisso tudo?". Esse projeto tem a possibilidade de proporcionar aos alunos interações, onde terá a construção de forma ativa, pois quando nós professores saímos da rotina de sala de aula, despertamos em nosso alunos a curiosidade, e a construção de novos conhecimentos.

Primeiramente foi feita uma visita de diagnóstico no zoológico com a finalidade de entender quais seriam as abordagens que montariam a sequência didática. Após essa consolidação, foram analisados os conteúdos trabalhados no livro didático no $7^{\circ}$ ano.

Após a identificação dos conteúdos foi elaborada uma ficha de coleta de dados (Figura 1). Essa ficha foi criada com o objetivo dos alunos durante a visita coletaram as informações necessárias que seriam depois discutidas em sala de aula com base nos conteúdos que foram trabalhados ao longo do ano letivo.

As turmas foram até o zoológico em datas diferentes (Figura 2), juntamente com a professora de Ciências (Figura 3). Durante a ida ao zoológico os alunos deveriam escolher três animais para coletar os dados correspondentes a sua ficha completando a mesma no local da coleta. Em cada ponto de coleta a professora explicava as principais características do grupo animal, onde os alunos poderiam usar essas informações para coletar os dados do animal que escolheram caso os dados não estivessem na placa de informação de cada animal no seu espaço.

Após essa coleta de dados, as atividades foram continuadas na semana paralela a ida ao zoológico. Em sala de aula, a professora dividiu a turma em pequenos grupos para os mesmos discutirem sobre os dados coletados durante a visita (Figura 4).

Após os alunos exporem seus dados a professora pontuou a importância da coleta de dados, explicitando a todos a finalidade da visita de estudo ao zoológico e utilizando a ficha de coleta para explicar os conceitos de nomenclatura, distribuição geográfica, temperatura entre outros. A ficha dos alunos foi entregue à professora para avaliar se os alunos tinham entendido a proposta da atividade. 
DOI: https://doi.org/10.46667/renbio.v14i2.592

Em outro momento a professora entregou a ficha de coleta e criou uma discussão sobre a "Biodiversidade Amazônica" utilizando os dados coletados pelos alunos. Durante a discussão os alunos participaram mostrando suas percepções sobre os seus animais, e por fim fizeram um texto sobre a importância de entender o que é a biodiversidade e de preservar a mesma.

\begin{tabular}{|c|c|}
\hline Nome Popular & \\
\hline Nome Cientifico & \\
\hline Nome em Inglês & \\
\hline Massa & \\
\hline Comprimento & \\
\hline Alimentação & \\
\hline Locomoção & \\
\hline Estrutura do corpo & \\
\hline Local de Origem geográfica & \\
\hline $\begin{array}{c}\text { Temperatura do ambiente } \\
\text { de origem geográfica }\end{array}$ & \\
\hline
\end{tabular}

Figura 1. Ficha de coleta de dados (CORRÊA, 2019).

\begin{tabular}{|c|c|c|c|}
\hline DATA & HORA & TURMA & ALUNOS \\
\hline $19 / 03$ & $08 \mathrm{~h} 30$ & 174 & 26 \\
\hline $19 / 03$ & $13 \mathrm{~h} 30$ & 171 & 34 \\
\hline $20 / 03$ & $08 \mathrm{~h} 30$ & 175 & 27 \\
\hline $20 / 03$ & $13 \mathrm{~h} 30$ & 172 & 36 \\
\hline $21 / 03$ & $13 \mathrm{~h} 30$ & 173 & 36 \\
\hline & & & 159 \\
\hline
\end{tabular}

Figura 2. Turmas que foram o zoológico (NASCIMENTO, 2019). 


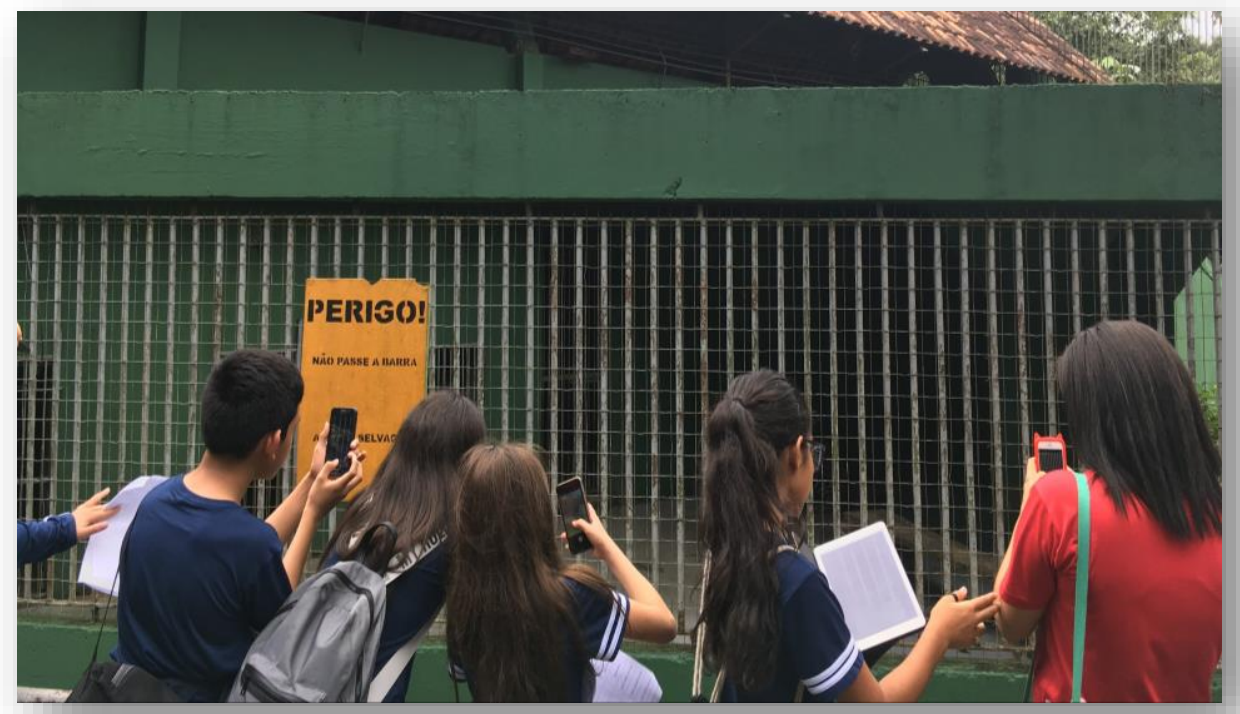

Figura 3. Acompanhamento da turma na coleta de dados (NASCIMENTO,2019).
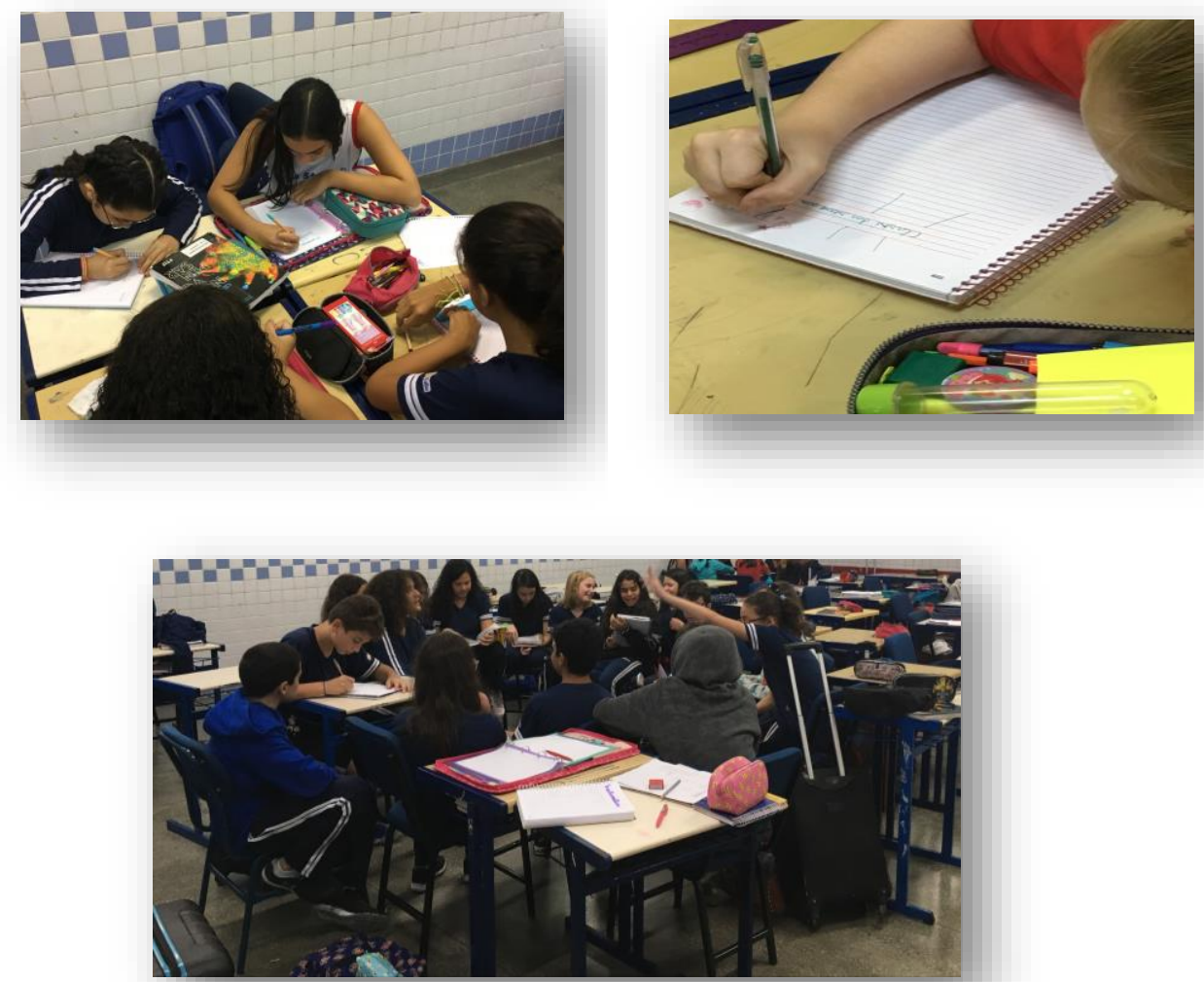

Figura 4. Discussões em sala de aula (NASCIMENTO, 2019). 


\section{Considerações finais}

A realização dessa atividade mostrou que a utilização de um procedimento de ensino dentro de uma visita de estudo exige planejar, organizar e selecionar o material que os alunos irão utilizar durante essa visita de estudo.

Dentro dessa perspectiva a utilização de uma sequência didática mostrou que os alunos não são apenas parte de um processo, mas sim protagonistas de uma ação pedagógica, onde os mesmos conseguem se enxergar dentro do processo de ensino aprendizagem, pois a atividade se mostra inovadora com relação às aulas expositivas de sempre.

$\mathrm{Na}$ disciplina de Ciências levar os alunos para atividades práticas sempre estimula o aprender, completando o que aprendem em sala e contribuindo para formar o conhecimento científico (ANDRADE, 2011).

Logo propor ferramentas diferentes para trabalhar assuntos nas disciplinas sempre será inovador e prazeroso para nossos alunos, os projetos educacionais são ótimos aliados nesse processo de viabilizar a inovação e criar possibilidades para esse momento.

Quando trabalhamos com projetos vemos que sua utilização serve como uma forma e facilitador de atividade, ação, onde os alunos participam no processo de produzir fatos sociais, trocar informações e construir conhecimento (ALMEIDA \& FONSECA JÚNIOR, 2000).

Utilizar o zoológico como projeto educacional, nos mostra que um espaço que parece, parece ser óbvio para uma aula de ciências pode ser inovador. Os livros que utilizamos na escola na maioria das vezes é totalmente descontextualizados com a realidade do aluno, onde os mesmo não podem explorar na prática o que encontram escrito nesses livros, sabemos que os livros não são adaptados a realidade do aluno, e as práticas dos professores são desenvolvidas a partir de critérios que são encontrados nesses livros. A situação nos mostra que o aprendizado do aluno apresentará falhas no seu processo de aprendizagem e seu conhecimento fica prejudicado.

Quando os projetos educacionais são bem alinhados, seus objetivos bem descritos tanto os alunos como os professores se sentiram motivados para superar seus conhecimentos, rompendo os limites que encontramos no ensino tradicional.

Quando transformamos o zoológico em uma ferramenta de ensino, convidamos tanto os professores como os alunos a saírem da sua zona de conforto (sala de aula), onde é um espaço que já sabem que terão explicações, provas, tarefas de casa. Utilizando espaços diferentes como o zoológico, os alunos perceberam que o auxílio visual facilitou o entendimento de muitos conceitos que foram não somente trabalhados na sequência didática, mas sim com o conteúdo trabalhando o ano inteiro. Quando os alunos viram algo que provavelmente somente leram nos 
DOI: https://doi.org/10.46667/renbio.v14i2.592

livros, aguçou o interesse e o mesmo pode relacionar o que observou durante sua ida ao zoológico.

O zoológico do CIGS é um ambiente que a maioria da população amazonense visitou, e para alguns alunos o ambiente não apresenta algo novo. Porém mostrar a diferença de um passeio para uma visita de estudo é um passo importante para expor para os alunos. O zoológico CIGS apresenta características que devem ser levados em consideração como por exemplo: o zoológico está situado dentro do perímetro urbano, abriga animais da fauna amazônica que são resgatados pelos soldados do exército, tem projetos de educação ambiental. Podemos observar que o local apresenta potencialidades para os professores desenvolverem atividades, onde os alunos façam no momento em que estão em uma visita de estudo e não se torna apenas um "passeio", mas sim uma sala de aula com muita relevância.

O zoológico apresenta um grande potencial como ferramenta para aproximar o ser humano da natureza, criando assim um sentimento de fazer parte desse ambiente. Quando esse sentimento de pertencimento não existe o indivíduo não valoriza o seu espaço, porém quando esse sentimento é criado o indivíduo se sente pertencente do local e cria sentimentos de respeito, de cuidado criando assim laços de pertencimento (LESTINHGE, 2004).

Quando falamos de Amazônia logo pensamos em um ambiente único e exuberante, caracterizado por apresentar uma biodiversidade riquíssima, onde o professor pode utilizar espaços como o zoológico para estabelecer essa conexão de pertencimento, através de metodologias dinâmicas, onde esse momento de estudo será significativo que serve de complementação para sala de aula.

Neste trabalho foi utilizado a sequência didática para que essas intervenções fossem feitas. Uma sequência didática é conceituada como um conjunto de matérias de ensino organizados e com a finalidade de permitir a aprendizagem de um determinado conteúdo (ZABALA, 1998).

A partir da sequência didática foram pensadas as competências e habilidades que se pretendia trabalhar com as turmas, inicialmente destacamos a competência geral sete da Base Nacional Comum Curricular, que trata da "[...] consciência socioambiental e o consumo responsável em âmbito local, regional e global. [...] cuidado de si mesmo, dos outros e do planeta." (BRASIL, 2017.), tendo em vista que foi trabalhado a diversidade de ecossistemas, a consciência de pertencimento ao ambiente e consciência crítica de preservação e consumo.

Ao utilizar a BNCC como documento normativo, significou que estava sendo assegurada as aprendizagens contextualizadas, tomando o conteúdo, apresentá-lo e conectandoo para torná-lo mais significativo e relevante, e a visita foi um facilitador para o desenvolvimento das aprendizagens. 
DOI: https://doi.org/10.46667/renbio.v14i2.592

Quando o documento normativo trata especificamente da área de ciências da natureza, é mencionado o processo investigativo com elemento central estando sujeito a situação didática, e foi o que se tentou desenvolver na atividade em questão, além das descrições do que o ensino de ciências deve desenvolver, neste ponto foi realizado um paralelo da BNCC com a sequência didática (Figura 5).

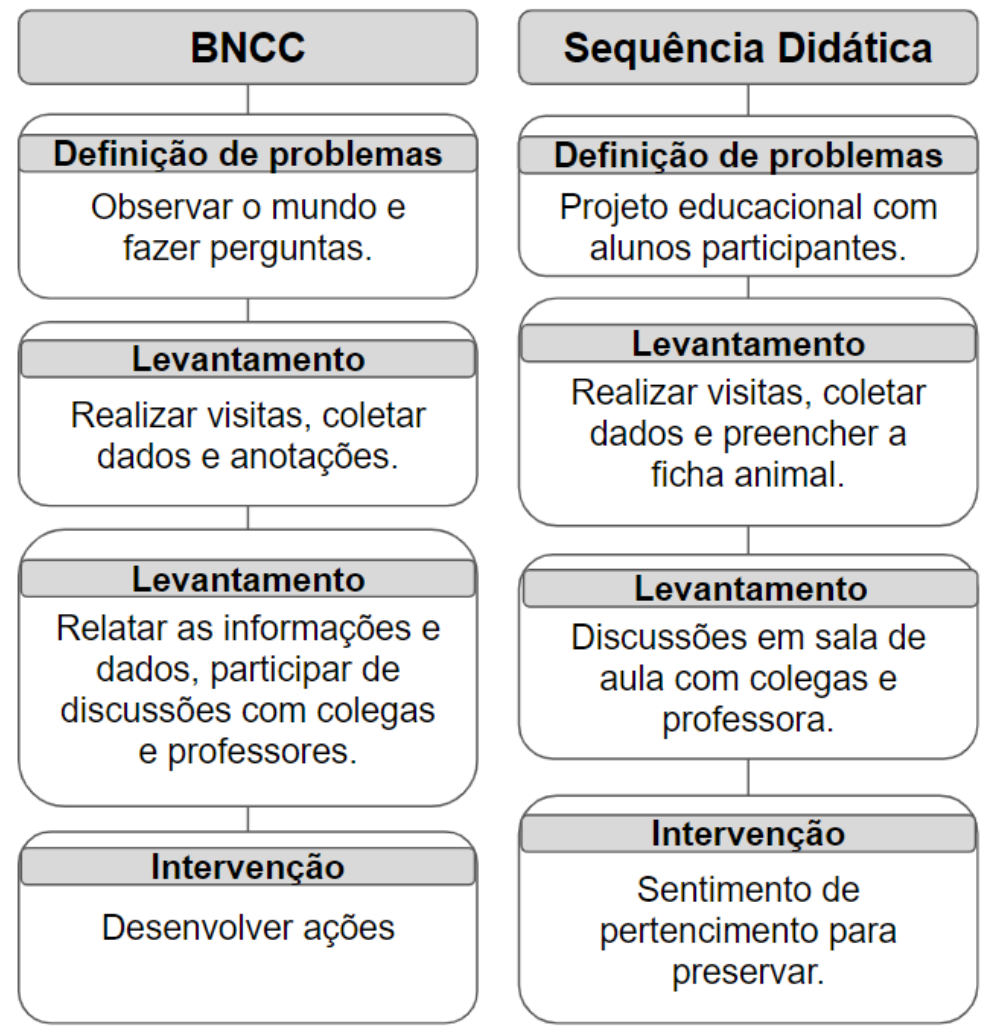

Figura 5. Diagrama BNCC e Sequência Didática (COSTA, 2020).

Com a sequência didática e a visita no zoológico do CIGS, foi trabalhada a unidade temática Vida e Evolução, o objeto de conhecimento foi a diversidade de ecossistemas e impactos ambientais, e as habilidades de caracterizar os principais ecossistemas brasileiros e avaliar os impactos provocados por suas populações afetam as espécies, seus hábitos, migrações e levam extinção. Ao conhecer o ecossistema que está inserido o aluno passa a entender o ambiente em que vive e se sente pertencente a esse ambiente, criando o sentimento de cuidado e valorização.

$\mathrm{O}$ adquirir de conhecimentos e habilidades para entender o ambiente em que vive, sua dinâmica e importância é um processo que será desenvolvido ao longo da vida de um cidadão, podendo iniciar-se na escola, por meio de atividades, interações com espaços como os zoológicos. As escolas ao proporcionarem atividades como visitas nesses espaços, acrescentam 
DOI: https://doi.org/10.46667/renbio.v14i2.592

experiências tanto no mundo em que esse aluno está inserido tanto como dentro da ciência e tecnologia, incentivando e ampliando os conhecimentos científicos.

A Base Nacional Comum Curricular apresenta uma de suas propostas, dentro das Ciências da Natureza, desenvolver a compreensão da dinâmica e funcionamento da natureza, através das implicações e intervenções científicas e tecnológicas no dia-a-dia das pessoas.

Ensinar Ciências na escola é algo muito importante, apresentar aos alunos a dinâmica do universo e como cada ser humano faz parte de tudo isso também, não é uma tarefa tão fácil, os alunos apresentam muitas dificuldades nesse processo de entender-se pertencente ao espaço.

Logo, é importante que os professores tenham a sensibilização em desenvolver atividades que proporcionem aos alunos a construção do conhecimento, considerando a compreensão desses conhecimentos e conceitos científicos na construção da cidadania.

As atividades práticas desenvolvidas dentro das Ciências da Natureza, deve proporcionar aos alunos vivências dentro do processo de construção de conhecimento, proporcionando a este aluno um desenvolver das habilidades de investigação científica, onde o aluno reflita sobre tudo o que faz e observa, cria hipóteses, faz seus próprios registros dessas construções.

Práticas educacionais, que levam os alunos a um momento de reflexão, possibilitam a formação de indivíduos com o sentimento de pertencimento e cidadania, envolvendo um processo de mudança de pontos de vista e conceitos. Quando esse aluno é levado para um ambiente que expressa uma característica de afetividade, como o zoológico, isso possibilita ao mesmo criar vivências e concepções sobre todo aquele momento.

A utilização de sequências didáticas dentro desse processo de investigações e reflexões associadas à educação em espaços não formais, desenvolve habilidades de investigação científica de grande valor para os alunos.

Portanto, considerar a utilização de espaços como os zoológicos associados a intervenções com a utilização de sequências didáticas, desenvolvem habilidades e valores, que os alunos irão desenvolver para tomar decisões e preservar o ambiente em que está inserido. 


\section{Referências}

ALMEIDA, F.J.; Fonseca Júnior, F.M. Projetos e ambientes inovadores. Brasília, DF: Parma, 2000.

ANDRADE, M. L. F.; MASSABNI, V. G. O desenvolvimento de atividades práticas na escola: um desafio para os professores de ciências. Ciência e Educação, Bauru, v. 17, 2011.

GARCIA, V. A. R. O processo de aprendizagem no Zoológico de Sorocaba: análise da atividade educativa visita orientada a partir dos objetos biológicos. Dissertação (mestrado em Educação) - Faculdade de Educação, Universidade de São Paulo. São Paulo: USP, 2006.

LESTINHGE, Sandra Regina. Olhares de educadores ambientais para o estudo do meio e pertencimento. 2004. Dissertação (doutorado em Recursos Florestais) - Escola Superior de Agricultura “Luiz de Queiroz”, Universidade de São Paulo. Piracicaba, 2004.

MERGULHÃO, M. C. Zoológico: uma sala de aula viva. São Paulo: Faculdade de Educação da USP. Dissertação, Mestrado em Educação. 1998.

ZABALA, Antoni. A prática educativa: como ensinar. Porto Alegre: Artmed, 1998.

Recebido em abril de 2021. Aprovado em outubro de 2021

Revisão gramatical realizada pelos autores 